\title{
Statoliths of the whelk Buccinum undatum: a novel age determination tool
}

\author{
P. R. Hollyman ${ }^{1, *}$, M. J. Leng ${ }^{2}$, S. R. N. Chenery ${ }^{3}$, V. V. Laptikhovsky ${ }^{4}$, \\ C. A. Richardson ${ }^{1}$ \\ ${ }^{1}$ School of Ocean Sciences, College of Natural Sciences, Bangor University, Menai Bridge, Anglesey LL59 5AB, UK \\ ${ }^{2}$ NERC Isotope Geosciences Facilities, British Geological Survey, Nottingham NG12 5GG, UK \\ ${ }^{3}$ Centre for Environmental Geochemistry, British Geological Survey, Nottingham NG12 5GG, UK \\ ${ }^{4}$ Centre for Environment, Fisheries and Aquaculture Science (CEFAS), Pakefield Road, Lowestoft, Suffolk NR33 0HT, UK
}

\begin{abstract}
Sustainability within the fisheries of the commercially important European whelk Buccinum undatum has become a major concern because of over-exploitation and increased landings in many European coastal shelf seas due to the expansion of export markets to East Asian countries. Current management of $B$. undatum populations is difficult to achieve as several life history traits are problematic to accurately monitor. The current method of age determination for stock assessment has a low success rate and focuses on the use of putative annual rings on the surface of the organic operculum. Here, we validate an annual periodicity of growth ring formation in $B$. undatum statoliths that provides an alternative, reliable and accurate method for determining a whelk's age. Laboratory-reared juvenile $B$. undatum of known provenance and age deposited a hatching ring at the time of emergence from their egg capsule and a clearly defined growth ring during February of their first and second years. Stable oxygen isotope profiles from the shells of 2 adult whelks confirmed annual growth ring deposition by demonstrating seasonal cycles of $\delta^{18} \mathrm{O}$ in the shell that matched the relative position and number of visible growth rings in the statolith. Validation of annually resolved statolith growth rings will, for the first time, provide fisheries scientists with a tool to determine the age structure of $B$. undatum populations and allow analytical stock assessments that will enable informed decisions for future management practices of whelk fisheries.
\end{abstract}

KEY WORDS: Buccinum undatum · Statoliths · Age determination · Fisheries monitoring · Oxygen isotope $\cdot$ Raman spectroscopy $\cdot$ Sclerochronology

\section{INTRODUCTION}

The common whelk Buccinum undatum is a commercially important species of marine gastropod fished in the coastal waters of the UK and across Northern Europe. In 2015, the UK landings of $B$. undatum by UK vessels totalled 20900 tonnes with a value at first sale of $£ 18.7$ million (MMO 2016). A large proportion of the whelk landings in the UK and Ireland supply an export market to East Asia that has grown steadily since the mid-1990s (Fahy et al. 2000) in response to recent increases in consumer demand

*Corresponding author: p.hollyman@bangor.ac.uk

$\S$ Advance View was available online April 24, 2017 which has driven the expansion of the fishery. However, declines in the number of whelks caught have been noted across European waters (Jersey, Shrives et al. 2015; Ireland, Fahy et al. 2005; North Sea/ Netherlands, Ten Hallers-Tjabbes et al. 1996) and has caused several local Inshore Fishery and Conservation Authorities (IFCA) to implement restrictions recently on pot and/or catch limits and the number of permits issued (Devon \& Severn IFCA 2016, Eastern IFCA 2016, Kent \& Essex IFCA 2016).

A reliable assessment of age and longevity in $B$. undatum is problematic for fisheries scientists, because

(C) The authors 2018. Open Access under Creative Commons by Attribution Licence. Use, distribution and reproduction are unrestricted. Authors and original publication must be credited. 
several of the species' life history traits are difficult to monitor at a population level. The lack of a planktonic larval stage and a relatively inactive adult lifestyle with no apparent migration (Pálsson et al. 2014) has led to the formation of discrete stocks which are vulnerable to overexploitation (Fahy et al. 2000). In many studies, these stocklets have been observed to show clear genetic and morphometric differences (e.g. Weetman et al. 2006, Shelmerdine et al. 2007, Magnúsdóttir 2010) including size at maturity, which can also differ markedly between sites (Haig et al. 2015, McIntyre et al. 2015, Shrives et al. 2015).

To resolve this conundrum, a reliable ageing method needs to be established for $B$. undatum so that accurate population age assessments and analytical stock assessments can be undertaken. The currently accepted method used by fisheries scientists, and validated by Santarelli \& Gros (1985), determines the age of whelks by reading growth rings on the operculum, an organic 'shield' that is used to protect the shell aperture when the animal withdraws into its shell. This is achieved by matching cycles in oxygen isotope composition from the shell to the numbers of growth rings observed on the opercula. However, this method traditionally has had a low success rate owing to the poor clarity of the rings, a problem highlighted by Kideys (1996) who reported that only $16 \%$ of 10975 opercula examined in whelks from the Isle of Man, UK, had 'clear and readable' rings, with a further $32 \%$ having 'readable' rings, leading to $48 \%$ of the samples being discarded. More recently, similar low levels of readability were found in several sites around the UK (Lawler 2013). The exclusion of large portions of samples due to poor clarity of the rings is likely to have biased the data; the constructed population growth curves were highly variable, presumably due to the ambiguity of the operculum readings.

Since whelks are becoming increasingly exploited, there is an urgent scientific need to underpin the fisheries stock assessment of their populations with accurate data concerning the age of individuals and their growth rates. For many mollusc species, the age of an individual can be determined by counting the annual growth lines present in longitudinal shell sections (See Richardson 2001 for review). This is particularly applicable to bivalve molluscs, but in gastropods it is not possible because there are often no obvious annual growth rings on or contained within their shells. Gastropod shells are also often problematic to analyse via sectioning as their coiled morphology makes it difficult to obtain a single clear growth axis using this technique.
Mollusc shells are repositories of information about the past environmental history of shell growth, and contain within the carbonate of their shells biogenic trace elements and oxygen isotopes at ratios $\left({ }^{18} \mathrm{O} /{ }^{16} \mathrm{O}\right.$, described as $\delta^{18} \mathrm{O}$ ) which are incorporated into the shell matrix at equilibrium during mineralisation (Wilbur \& Saleuddin 1983, Wheeler 1992). Seawater temperature at the time of shell formation can be reconstructed from the gastropod shell throughout ontogeny by determining $\delta^{18} \mathrm{O}$ along the growing axis of the shell (e.g. Rapana venosa, Kosyan \& Antipushina 2011 and Conus ermineus, Gentry et al. 2008). The empirical fractionation of oxygen isotopes in mollusc carbonates with changes in temperature are well known (e.g. Epstein et al. 1953). Oxygen isotopes are sourced from $\mathrm{H}_{2} \mathrm{O}$ and $\mathrm{CO}_{2}$ during shell formation (Leng \& Lewis 2016); more negative values of $\delta^{18} \mathrm{O}$ reflect warmer seawater temperatures whilst more positive values are indicative of cooler seawater temperatures (Grossman \& Ku 1986) at a constant $\delta^{18} \mathrm{O}$ of seawater. Sampling the shell carbonate at known intervals along the whorled axis of the shell and determining seasonal changes in $\delta^{18} \mathrm{O}$ allows the age (seasonality) of the shell to be determined. This approach, however, is not suitable for largescale ageing of whelk due to the cost of analysing the potentially huge numbers of samples needed to accurately reconstruct seasonality across a significant number of shells.

In lieu of being able to directly use the shells or opercula to estimate age, an alternative age registering structure was sought; whelks contain an accretory hard structure called a statolith which is the focus of this paper. Statoparticles (such as statoliths) are structures that are integral to the nervous system of a diverse range of animal groups including the Polychaeta (Beesley et al. 2000), Holothuroidea (Ehlers 1997), Crustacea (Espeel 1985) and several classes of the Mollusca e.g. the Bivalvia (Morton 1985), Gastropoda (Barroso et al. 2005, Chatzinikolaou \& Richardson 2007, Galante-Oliveira et al. 2013) and Cephalopoda (Arkhipkin 2005). These structures are used in gravity perception and are contained within a statocyst, which detects movement of the statoparticle indicating a change in orientation (Chase 2002). Commonly composed of calcium carbonate, they have a wide-ranging morphology across the phylum in which they are found. The statoparticles of gastropods (called statoliths) are often singular, roughly spherical granules (Richardson 2001, Galante-Oliveira et al. 2013). Gastropod statoliths can contain rings that are deposited annually (e.g. Nassarius reticulatus, Barroso et al. 2005; Neptunea 
antiqua, Richardson et al. 2005b; Polinices pulchellus, Richardson et al. 2005a) and are an archive of biota life history, containing information about age and seasonal temperature cycles (Richardson et al. 2005a, Galante-Oliveira et al. 2015) and their transition from a planktonic pelagic larval lifestyle to a benthic existence (Barroso et al. 2005, Richardson et al. 2005a, Chatzinikolaou \& Richardson 2007). Once the rings in the statolith have been deciphered, information about a gastropod's life history can be extracted to understand its ontogenic growth. Thus, these structures are potentially an invaluable resource for fisheries scientists, who could use this information to assess population age structure of commercially important gastropod species such as B. undatum.

Here we demonstrate, for the first time, that growth rings in the statoliths of $B$. undatum are annually deposited like those within the opercula, and can be used for the reliable age estimation of the species. The timing of statolith growth ring formation was determined in whelks of known age and life history that had been reared in the laboratory under ambient seawater temperatures for $2 \mathrm{yr}$ following their emergence from egg capsules. The structure of the statoliths was also investigated to determine general morphology and mineralogical composition. We then used shell $\delta^{18} \mathrm{O}$ profiles drilled from around the whorl and compared these data with the matching whelk statolith growth lines.

\section{MATERIALS AND METHODS}

\section{Field collection}

Approximately 200 whelks (>25 mm shell length) were trapped and collected in February 2015 from a site in the Menai Strait (North Wales, UK; $53.235556^{\circ},-4.141835^{\circ}$, depth 10 to $11.5 \mathrm{~m}$ ) using a string of 3 baited scientific inkwell pots laid for $24 \mathrm{~h}$. The drainage holes in the pots were covered with $3 \mathrm{~mm}$ mesh and the whelk catch was not riddled (a process used by fishermen to remove undersized whelks) to ensure all size classes were retained for analysis. Dispensation for the landing of undersized whelks $(<45 \mathrm{~mm})$ was granted by the Welsh Government (disp\#004). Once collected, whelks were frozen until required, whereupon they were thawed and the body removed from the shell using forceps to gently pull the foot and detach the collumellar muscle. Shell height (aperture to spire length) was measured to the nearest $1 \mathrm{~mm}$ using Vernier callipers, total body weight was recorded to the nearest $0.1 \mathrm{~g}$ and reproductive maturity was assessed using the scale of Haig et al. (2015). The body of each whelk was re-frozen for later statolith extraction.

\section{Laboratory experiment}

This experiment was designed to study the formation of the whelk statolith during ontogeny and to determine the timing of growth ring formation. Seven whelk egg masses that had been laid naturally in an intertidal location at Tal-y-Foel $\left(53.158512^{\circ}\right.$, $-4.279493^{\circ}$ ) in the Menai Strait were collected in November 2013 and 2014. Egg masses were transported to the laboratory and held in aquaria supplied with flowing ambient seawater from the Menai Strait. Approximately 2 mo later, juvenile whelks hatched directly from the egg capsules and were reared for 1 yr (2014 hatching) and 2 yr (2013 hatching) under an approximate $10 \mathrm{~h}$ light:14 h dark cycle, being fed regularly thrice weekly with small pieces of frozen and thawed mackerel Scomber scombrus. Each month for $24 \mathrm{mo}, 10$ whelks were removed and frozen for later statolith extraction.

\section{Statolith extraction and ageing}

Selected individuals of the frozen field-caught adult and laboratory-reared juvenile whelks were thawed $(3 \mathrm{~h})$ and their bodies bisected (see Fig. 1a). Each half of the whelk body was examined under a low-power binocular microscope to locate, dissect and remove, using fine forceps $(0.10 \times 0.06 \mathrm{~mm}$ tip $)$, a pair of statocyst sacs (left and right side), each containing a statolith (see Fig. 1b). Incident illumination as well as transmitted light were used during the dissections and highlighted the statoliths as small shadows beneath the cerebral ganglion (see Fig. 1c). The $<0.75 \mathrm{~mm}$ statocysts were transferred to a watch glass with a drop of Milli- ${ }^{\circledR}$ ultrapure water (Merck Millipore), then torn open and the statoliths removed using a hypodermic needle ( $0.5 \mathrm{~mm}$ diameter). Where necessary, each statolith was cleaned of any adhering tissue by immersion in $20 \%$ sodium hydroxide $(\mathrm{NaOH})$ for 30 min and rinsed in Milli- $\mathrm{Q}^{\circledR}$ quality water. Once the statoliths had air-dried they were mounted on a microscope slide using Crystalbond ${ }^{\mathrm{TM}}$ 509 thermoplastic resin and imaged under a Meiji Techno MT8100 microscope with a Lumenera Infinity 3 microscope camera at $40 \times$ magnification. This allowed visualisation of the statolith growth rings, 
which could then be counted and the statolith diameters measured using ImageJ v.1.48 (Ferreira \& Rasband 2012) (see Fig. 2).

\section{Scanning electron microscopy}

Several statoliths from the right and left side of small and large whelks were selected for structural analysis. Each statolith was mounted in Crystalbond ${ }^{\mathrm{TM}} 509$ on an aluminium scanning electron microscopy (SEM) stub and imaged as above. The statolith was ground by hand to the central plane using progressively finer 400,1200, 2500 and 4000 silicon carbide grinding papers lubricated with Milli$\mathrm{Q} \bigotimes$ quality water. Each statolith was finally polished with a $1 \mu \mathrm{m}$ diamond suspension gel and thoroughly cleaned with detergent and water and dried before submersion in $0.1 \mathrm{M}$ hydrochloric acid for $2 \mathrm{~min}$ to etch the exposed statolith surface. The exposed and etched statolith surfaces were then imaged using a FEI QUANTA 600 environmental SEM operated in low vacuum mode, with an electron beam accelerating voltage of 12.5 to $15 \mathrm{kV}$, a beam probe current of 0.14 to $0.26 \mathrm{nA}$, and a working distance of 10.6 to $10.9 \mathrm{~mm}$.

\section{Micro-Raman spectroscopy}

Micro-Raman spectroscopy (MRS) allows differentiation between the polymorphs of $\mathrm{CaCO}_{3}$ (amorphous $\mathrm{CaCO}_{3}$, calcite, aragonite and vaterite) by focussing a laser light onto the statolith surface. Inelastic scattering of the incident light occurs after contact with the sample structure due to interaction with the vibrational levels of the composite molecules causing a shift in the wavelength of the measured scattered photons (Raman shift) (Higson 2006). The wavelength shifts of the spectra are predictable in position and intensity for different substances. For $\mathrm{CaCO}_{3}, 2$ main wavelength regions of the spectra are of interest: peaks in the 100 to $350 \mathrm{~cm}^{-1}$ range pertain to interaction with features of the external lattice structure, whereas peaks in the 600 to $1800 \mathrm{~cm}^{-1}$ range relate to interactions with the internal molecular planes (Parker et al. 2010). To determine the statolith composition, individual statoliths were fractured using fine-tipped forceps $(0.10 \times 0.06 \mathrm{~mm}$ tip) to reveal the inner growth axis and analysed with MRS (Reinshaw InVia Raman-Microscope) at the Diamond Light Source, Harwell, UK. The MRS consisted of a $473 \mathrm{~nm}$ laser at a power of $15 \mathrm{~mW}$ and was focussed using a lens with a magnification of

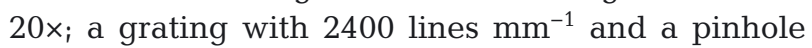
size of $100 \mu \mathrm{m}$ were used for spectra acquisition. The spectra were acquired between 100 and $3200 \mathrm{~cm}^{-1}$. Three sample spots were taken approximately equidistant along the interior growth axis of 3 statoliths from the central nucleus to the outer edge, although the results from only 1 statolith are presented. Synthetic calcite and speleothem aragonite standards (Brinza et al. 2014) were analysed prior to and after statolith analyses and the resulting Raman spectra were adjusted using a polynomial background correction. Following MRS, the fractured statolith surface was imaged using SEM to obtain a detailed image of the sampled surface.

\section{Isotope ratio mass spectrometry}

The outer periostracum and any adhering material were cleaned from the shells of an adult male and female whelk collected from the Menai Strait using a stiff-bristled brush and tap water, and then air-dried. The shell surface was abraded using a $1 \mathrm{~mm}$ diamond burr attached to a Dremel@ 4000 rotary tool to remove any contamination from the shell surface. A sampling axis around the entire whorled growth was marked out close to the shoulder of the shell whorl with $1 \mathrm{~mm}$ notations along its length. Tracks $(1 \times 10 \mathrm{~mm})$ were drilled at a resolution of $2 \mathrm{~mm}$ at the apex and most recently formed whorl, the oldest and youngest parts of the shell, and at $4 \mathrm{~mm}$ for the central portion where growth is fastest, in line with the visible growth striations. Care was taken to only sample the outer prismatic layer of the shell and not drill into the inner nacreous layers, which are deposited at a later time. The drilled $\mathrm{CaCO}_{3}$ samples were collected on small square $(2 \times 2 \mathrm{~cm})$ sheets of greaseproof paper transferred to a labelled $0.5 \mathrm{ml}$ Eppendorf tube. This sampling strategy was extended as close to the tip of the shell as possible; however, in all cases the earliest shell growth (top 1 to $1.5 \mathrm{~cm}$ ) could not be sampled owing to shell damage and resolution of drilling.

Approximately 50 to $100 \mu \mathrm{g}$ of powdered carbonate sample were used for isotope analysis using an IsoPrime dual inlet mass spectrometer plus multiprep device (at the British Geological Survey). Weighed samples were added to glass vials which were then evacuated, and anhydrous phosphoric acid $\left(\mathrm{H}_{3} \mathrm{PO}_{4}\right)$ was added to each sample at $90^{\circ} \mathrm{C}$. The samples were left to digest for $15 \mathrm{~min}$ and the expressed gas was collected, cryogenically cleaned to remove any mois- 
Fig. 1. (a) Ventral view of a female Buccinum undatum removed from its shell, showing the siphon (s), mantle (m) proboscis (p), operculum (op), foot (f), and tentacles (t) (the digestive gland [dg] and gonad $[g]$ are out of frame). Dashed line: bisection of the whelk. (b) Half a bisected $B$. undatum illuminated using transmitted light and viewed in a dissection microscope, showing the cerebral ganglion (cg) and statolith (st). Dotted line: area of interest shown in (c). (c) A statolith following removal, showing nerve (n), statolith (st) and statocyst (sc)
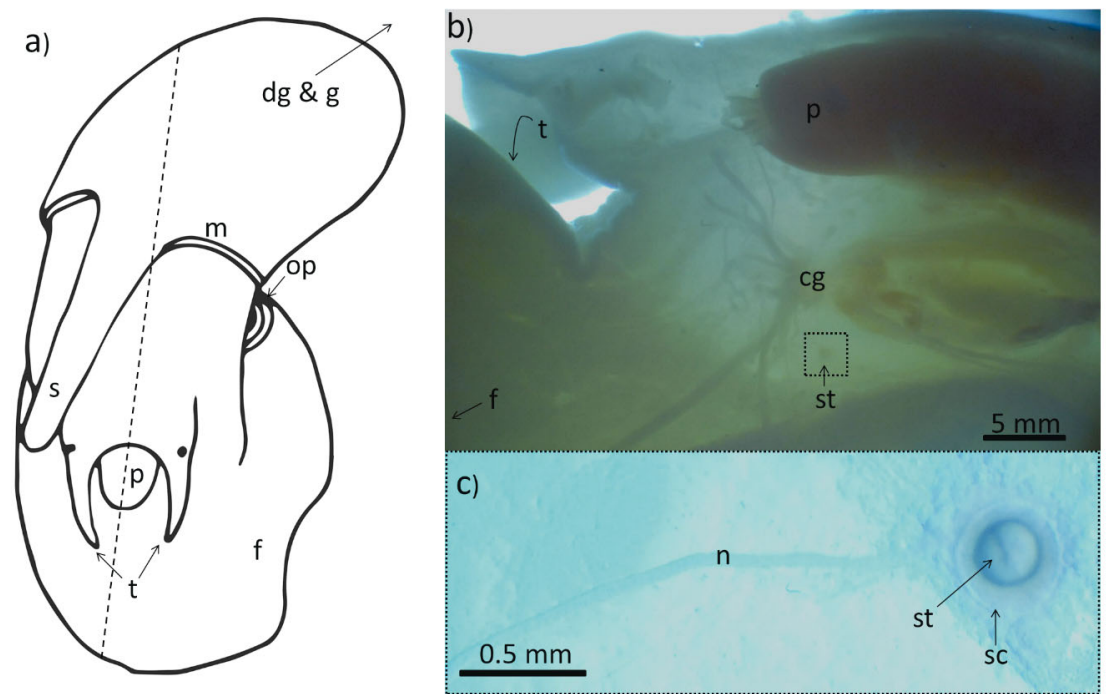

ture and passed into the mass spectrometer. Isotope values $\left(\delta^{13} \mathrm{C}, \delta^{18} \mathrm{O}\right)$ are reported as per mille (\%) deviations of the isotopic ratios $\left({ }^{13} \mathrm{C} /{ }^{12} \mathrm{C},{ }^{18} \mathrm{O} /{ }^{16} \mathrm{O}\right)$ calculated to the VPDB scale using a within-run laboratory standard (KCM) calibrated against NBS-19. The aragonite-acid fractionation factor applied to the gas values was 1.00855 (Sharma \& Clayton 1965). A drift correction was applied across the run, calculated using the standards that bracket the samples. The Craig correction was also applied to account for the influence of $\delta^{17} \mathrm{O}$ within the sample (Craig 1957). The average analytical reproducibility of the standard calcite (KCM) is $0.05 \%$ for $\delta^{13} \mathrm{C}$ and $\delta^{18} \mathrm{O}$. The resulting $\left({ }^{18} \mathrm{O} /{ }^{16} \mathrm{O}\right.$ ratio) data were treated with a 5 -point Savitsky-Golay smoothing filter (Steinier et al. 1972). The $\delta^{13} \mathrm{C}$ data are not presented here.

\section{RESULTS}

\section{Statolith location and morphology}

Each whelk has 2 statocysts in the tissues of its foot, and each statocyst contains a single roughly spherical statolith $(<0.75 \mathrm{~mm}$ in diameter) (Fig. 1b). Orientation of the statolith in resin in a dorsal-ventral position shows a circular outline shape and is the optimum position to view and measure the visible growth rings (Fig. 2a). Laterally, the statolith has an oval shape (Fig. 2b) and has a dorso-ventrally compressed spherical shape where the rings are less clear. Thus, to maintain consistency and to maximise the visibility of the rings, all analyses/images were undertaken from statoliths orientated in a dorsalventral view.
The relationship between statolith diameter and shell length was shown to display a power relationship (Fig. 3a). This was investigated further using the 'smatr' package (Wharton et al. 2015) in R to analyse the $\log _{10}$ transformations of each variable (Fig. 3a inset). A significant correlation was found between the 2 variables $(p<0.001)$ with a slope of 0.438 (lower and upper $95 \%$ CI: 0.432 and 0.443 respectively). This shows the relationship has negative allometry, indicating that statoliths and shells do not grow proportionally. Instead, the growth of the statoliths decreases in comparison to the shell length over time. This results in smaller whelks having proportionally larger statoliths in comparison to shell length. The data in Fig. 3a closely fit the line for whelks $<60 \mathrm{~mm}$, allowing estimates of shell length to be determined from the diameter of the rings. However, above this size there is wide variation in statolith diameter. By measuring the

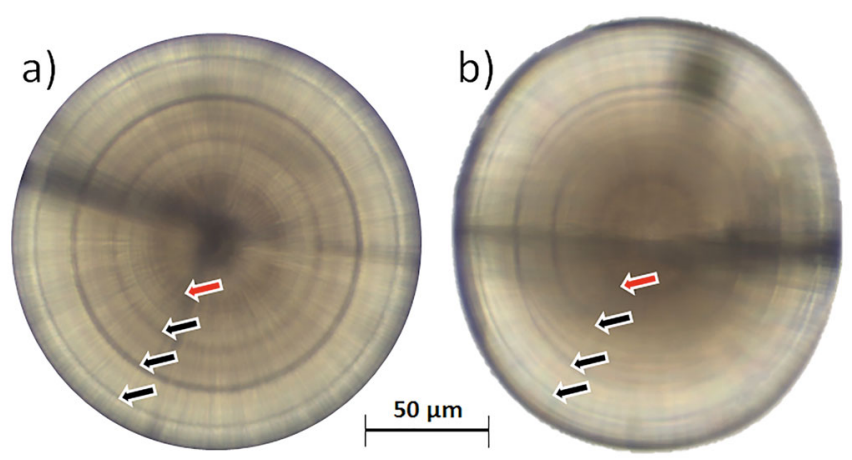

Fig. 2. Photomicrographs of 2 statoliths removed from an individual Buccinum undatum collected from the Menai Strait. (a) Dorso-ventral view; (b) lateral view. Annual growth rings are marked with arrows and hatching rings with red arrows in each statolith orientation 

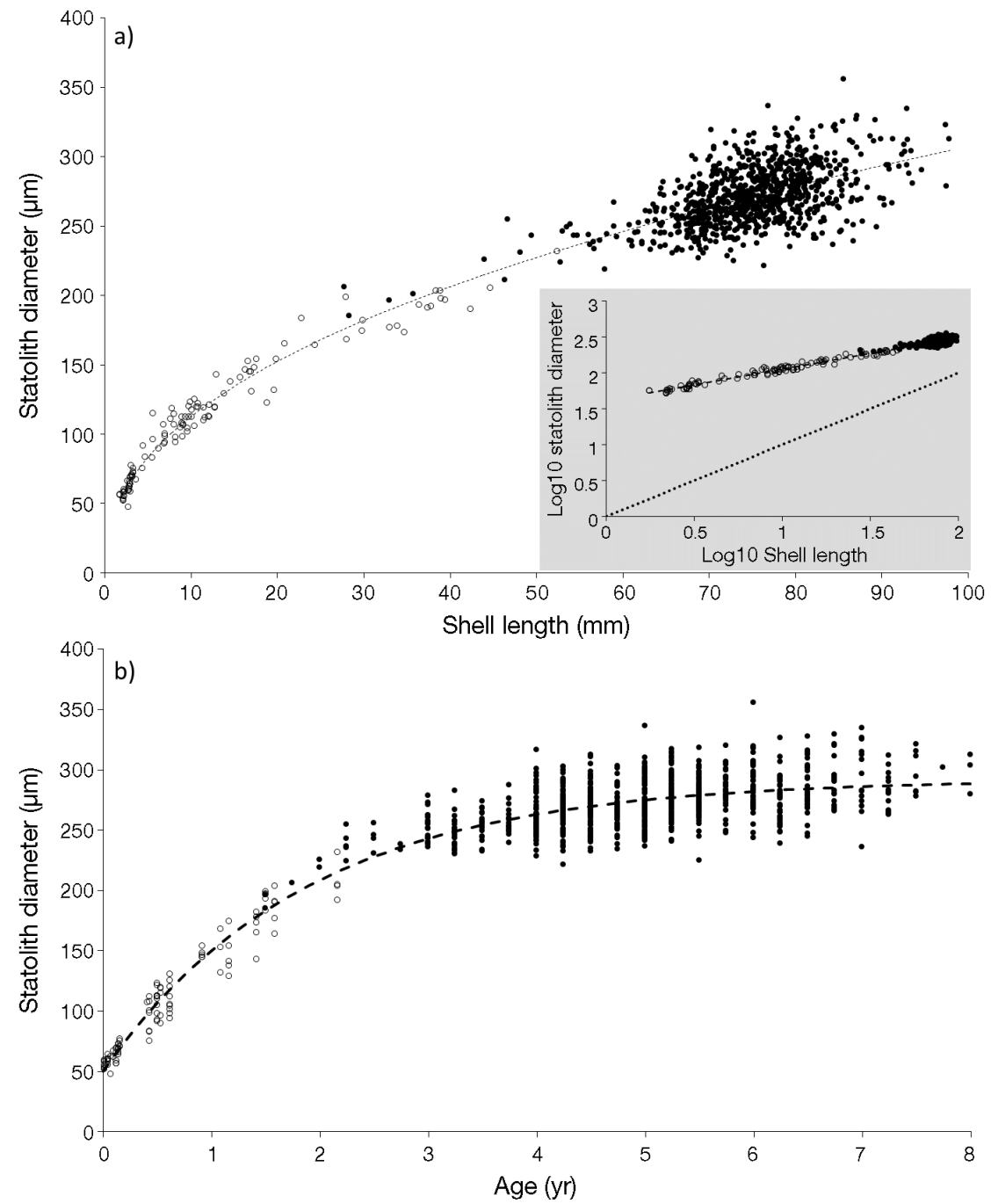

Fig. 3. (a) Relationship between Buccinum undatum shell length and statolith diameter, showing field-collected whelks (filled circles), and laboratoryreared juveniles (empty circles), fitted with a power function line (dotted line; $\left.y=41.38 \times x^{0.4354} ; \mathrm{R}^{2}=0.96\right)$. Inset: scatterplot showing the relationship between $\log _{10}$ statolith diameter and $\log _{10}$ shell length of field-collected individuals (filled circles), and laboratory-reared juveniles (empty circles). The slope of the linear relationship (dashed line) is $0.43\left(\mathrm{R}^{2}=0.96\right)$. Dotted line represents an isometric relationship. (b) Scatterplot showing the relationship between statolith diameter and age, constructed from statolith rings from field-collected (filled circles) and laboratory-reared animals of known age (empty circles), fitted with a von Bertalanffy growth curve $\left(R^{2}=0.90\right) . n=931$ for all plots analysis $(\mathrm{n}=800)$. In total, $48.6 \%$ of the samples were classed as 'clear and readable' and a further $43 \%$ as 'readable (using the same criteria as Kideys 1996), thus only $8.4 \%$ of samples were excluded.

\section{Statolith structure}

The broken statolith shown in Fig. 4a is composed of aragonite. All 3 of the analysed statoliths displayed the characteristic peaks for aragonite. The Raman spectra extracted between 100 and $750 \mathrm{~cm}^{-1}$ demonstrate a coincidence of peaks at 151, 183 and $206 \mathrm{~cm}^{-1}$ and a wide peak at 702 to $706 \mathrm{~cm}^{-1}$, for the 3 sample spots from the statolith as well as the aragonite standard (Fig. 4b). A shoulder is also visible on the $151 \mathrm{~cm}^{-1}$ peak at $143 \mathrm{~cm}^{-1}$. By contrast, the calcite standard peaks at 155, 281 and $712 \mathrm{~cm}^{-1}$ indicate that this statolith contains no trace of calcite. Fig. 4c shows an additional peak between 2850 and $3000 \mathrm{~cm}^{-1}$ for the 3 sample spots. Peaks in this range are thought to be indicative of $\mathrm{C}-\mathrm{H}$ functional groups found within organic matter (Smith \& Dent 2005), and thus are likely indicative of the presence of an organic component within the crystal matrix. Fig. 5 shows the agreement between the visible rings in the optical microscope (OM) image of a whole statolith (Fig. 5a) and the exposed acid-etched SEM image of the central plane of the paired statolith (Fig. 5b). The clarity of the rings in Fig. 5b suggests that a clear structural change has occurred during the formation of a growth ring. statolith diameter at successive rings for whelks $<60 \mathrm{~mm}$ it is feasible to reconstruct shell length at each ring. Fig. 3b shows the relationship between statolith diameter and age (ascertained from statolith rings in field-caught whelks), fitted with a von Bertalanffy growth curve $\left(\mathrm{R}^{2}=0.90\right)$. Although it is a strong relationship, there are large amounts of overlap between ages. The clarity of the statoliths was also very high, with the vast majority of samples included in the

\section{Hatching ring and growth ring formation}

The inner opaque area seen in Fig. 5a signifies the period of development in the egg culminating in the formation of a hatching ring. The hatching ring can also be seen and appears in January when these animals hatched (Fig. 6a-d). For the 2013 juvenile cohort, the hatching ring was deposited at a statolith 

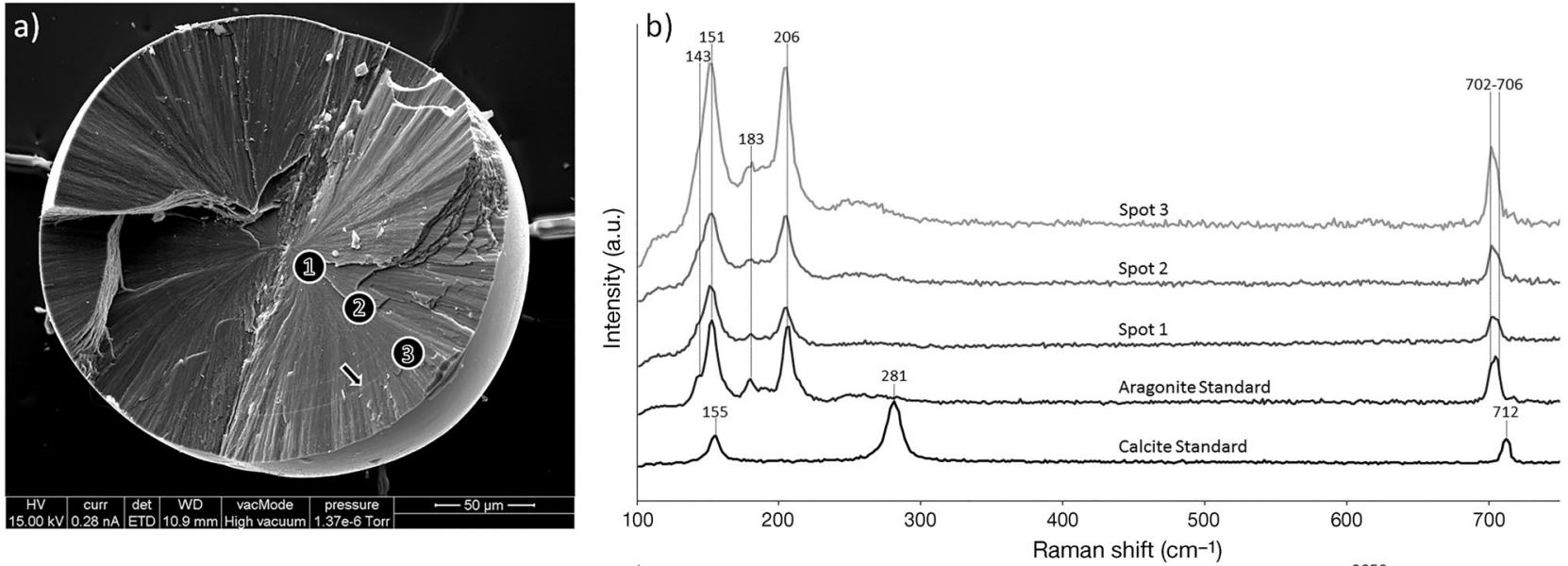

Fig. 4. (a) Scanning electron microscope image of a cracked statolith with the central plane exposed. The sample spots (1-3) used for micro-Raman analysis are shown with circles; arrow highlights a clear growth ring coincidentally sampled with spot 3. (b) Raman spectra from the 3 sample spots together with the aragonite and calcite standards. Raman spectra acquired from 100 to $750 \mathrm{~cm}^{-1}$ are displayed. (c) Raman spectra for the 3 sample spots extracted between 1500 and $3200 \mathrm{~cm}^{-1}$ ( $y$-axis presented as arbitrary units)

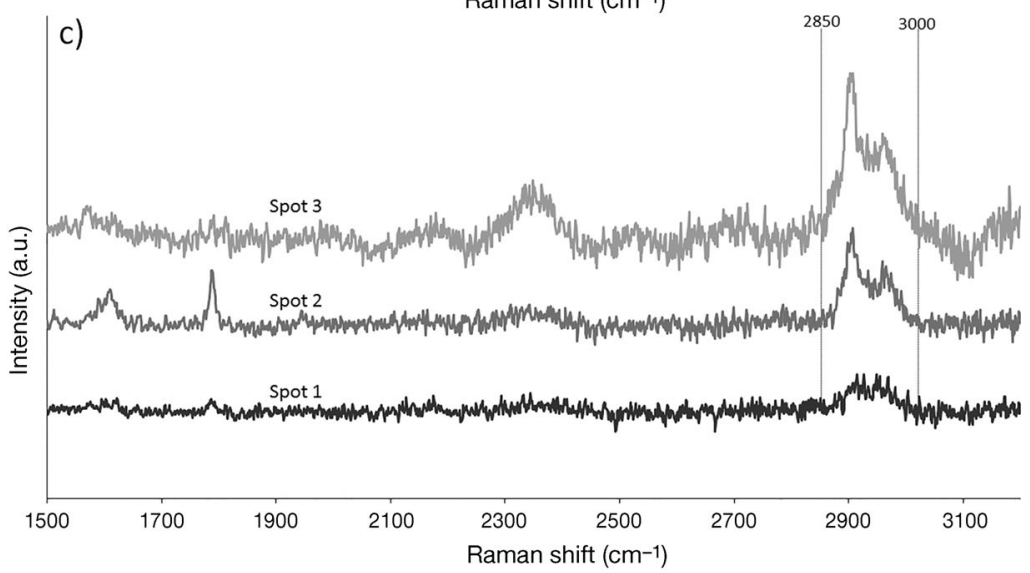

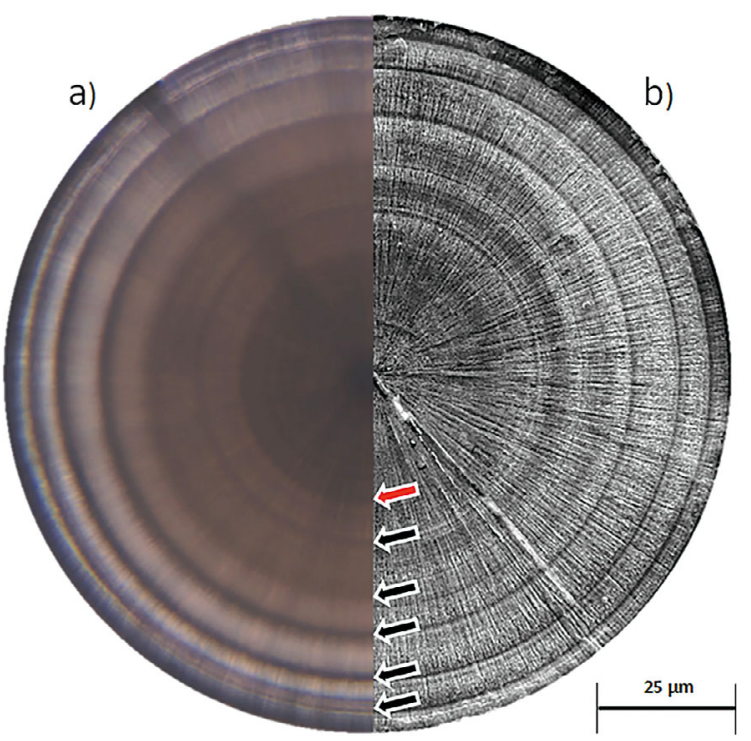

Fig. 5. Composite image of 2 statoliths from the same Buccinum undatum specimen. (a) Photomicrograph of an extracted and mounted left hand statolith imaged using optical microscopy; (b) scanning electron microscope image of the matching right hand statolith that has been resin-mounted, ground to the central plane, polished and etched. Annual growth rings highlighted with black arrows, hatching ring highlighted with red arrow diameter of $53.6 \pm 4 \mu \mathrm{m}$ (mean $\pm 1 \mathrm{SD}, \mathrm{n}=30$ ) and for the 2014 cohort, at $55.1 \pm 6 \mu \mathrm{m}(\mathrm{n}=30)$. The data from the 2 cohorts were not significantly different (independent $t$-test, $\mathrm{p}=0.1$ ). The central opaque area (larval growth) seen in Fig. 5a is surrounded by a less opaque region containing weak and diffuse rings. This pattern is also mirrored in Fig. 6, which shows the ontogenetic development of statoliths removed from laboratory-reared animals of different ages between 2 wk and 2 yr. Clear disturbance rings can be seen in the increment following hatching ring deposition and are a common feature of adult statoliths. The clear Year 1 ring in the statolith in Fig. 6d marks a colour change from brown to light brown and was deposited in February during the coldest part of the annual temperature cycle. A similarly positioned ring can be seen in Fig. 5a, signifying the first annual ring formation. The colour change is regularly seen in statoliths taken from field-caught adult whelks and is a good indicator of the position of the first annual growth ring. Following deposition of the slightly unclear first annual ring, subsequent annual rings are clearly delineated in both OM and SEM images (Fig. 5a,b). Disturbance rings (a common fea- 


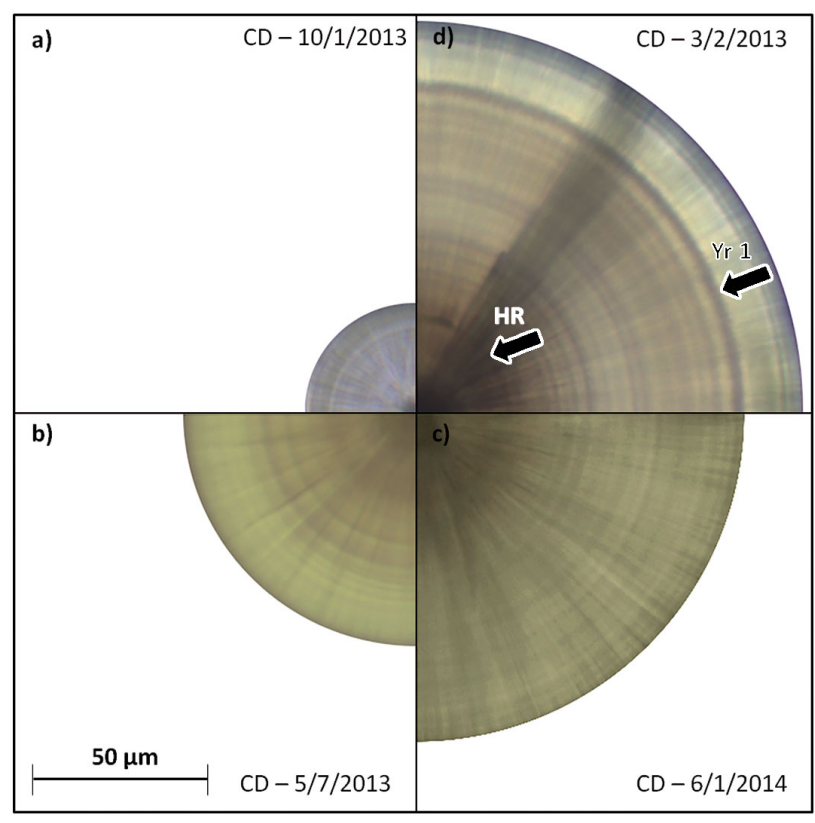

Fig. 6. Composite image showing seasonal juvenile statolith development at (a) 2 wk after hatch, (b) 6 mo after hatch, (c) $1 \mathrm{yr}$ after hatch and (d) $2 \mathrm{yr}$ after hatch. In all cases the hatching ring (HR) is visible, as are multiple faint disturbance lines. The $1 \mathrm{yr}$ ring (Yr 1 ) is also visible in the image from the 2 yr old individual. CD: collection date $(\mathrm{d} / \mathrm{mo} / \mathrm{yr})$

ture of the statoliths in younger whelks) are typically much weaker in definition than the clear annuallyresolved rings.

\section{Annual growth ring validation}

Fig. 7 shows the coincidence between statolith ring position (Fig. $7 \mathrm{C}, \mathrm{f}$ ) and maximum values in the shell $\delta^{18} \mathrm{O}$ cycles (Fig. 7a,d). Maximum $\delta^{18} \mathrm{O}$ represents minimum seawater temperatures. The $3 \delta^{18} \mathrm{O}$ minima in the female shell (Fig. 7a) match the position of the 3 statolith rings (Fig. $7 \mathrm{C}$ ) and the 4 maxima seen in the male shell (Fig. $7 \mathrm{~d}$ ) match the 4 statolith rings (Fig. 7f). In both shells, the tip of the apex was not sampled, represented by the grey hatched area in Fig. $7 \mathrm{a}, \mathrm{d}_{i}$ the point at which sampling ceased is indicated by a black arrow (Fig. 7b,e).

\section{DISCUSSION}

This study validates, for the first time, the annual periodicity of growth rings found within the statoliths of the common whelk, Buccinum undatum, as well as investigating their structure and composition. This was achieved using a combination of laboratory rear- ing of juvenile specimens and geochemical analysis of both statoliths and shells from wild-collected adults. The validation of the annual growth lines as a reliable ageing tool will provide an alternative to the currently used and often unreliable operculum.

\section{Visualization, interpretation and timing of statolith ring formation}

In a previous study following extraction and statolith cleaning, Richardson et al. (2005a) hand-ground and polished the statoliths of the neogastropd Neptunea antiqua to observe the growth rings. However in the current study, when $B$. undatum statoliths were hand-ground (using the above-described methods for SEM preparation) and observed in the optical transmitted light microscope, weaker disturbance rings became more apparent and often obscured the earliest annual growth rings due to the removal of the overlying statolith structure, which often masked them. However, when a whole statolith was observed the weaker lines were less apparent; this approach was adopted throughout the study.

A single, clear growth ring was deposited annually within the statoliths of the laboratory-reared juveniles during February and March when seawater temperatures were minimal in the Menai Strait. Female $B$. undatum lay egg capsules in which larvae develop, and juveniles hatch directly, leaving their egg capsules without a planktonic larval stage. The first identifiable diffuse statolith ring deposited can be termed a 'hatching ring', which is formed as the juveniles emerge from their capsules. The hatching ring has a similar position in the statolith to the settlement ring in statoliths from Polinices pulchellus (Richardson et al. 2005b) and Nassarius reticulatus (Barroso et al. 2005, Chatzinikolaou \& Richardson 2007), which hatch from egg capsules and undergo a planktonic larval existence prior to settlement. Thus, importantly, these 2 kinds of juvenile rings in gastropods with different early life strategies represent the same life history event i.e. the transition from larvae to juvenile. Whilst hatching ring diameters in reared $B$. undatum juveniles are fairly constant (53.6 to $55.1 \mu \mathrm{m})$, it has been shown that maternal size directly influences egg capsule size and subsequent juvenile hatching size, which in turn can also be mediated by intra-capsular cannibalism (Nasution 2003, Nasution et al. 2010, Smith \& Thatje 2013). Therefore, in a population with larger than average sized whelks, the hatching ring will be larger than the average observed here. A strong relationship 

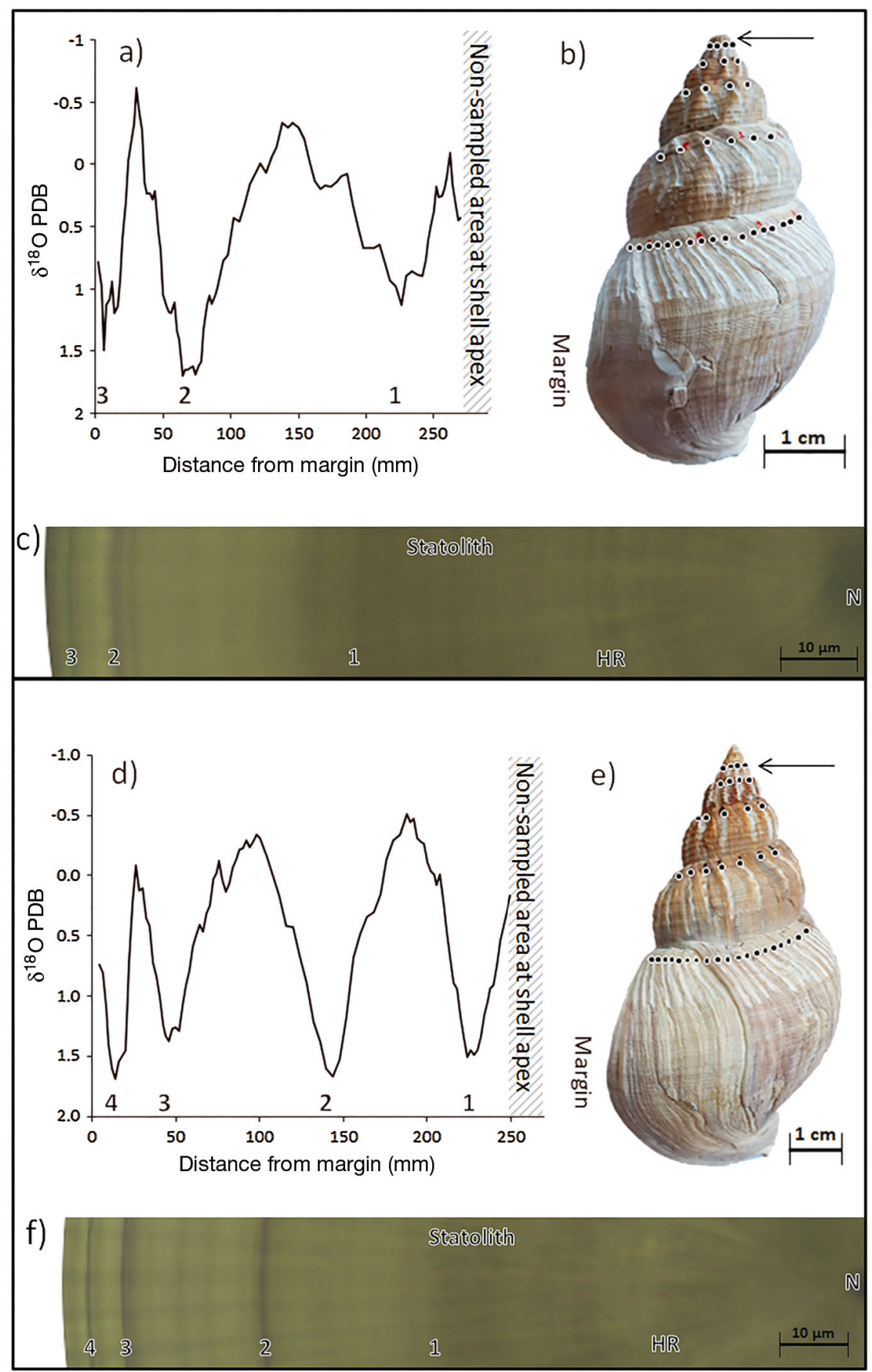

Fig. 7. Comparison of the shell $\delta^{18} \mathrm{O}$ profiles with the associated statolith for 2 Buccinum undatum. (a) $\delta^{18} \mathrm{O}$ profile from the shell of a female $B$. undatum; note that the $y$-axis is inverted to show the position along the shell of the positive peaks in the $\delta^{18} \mathrm{O}$ cycles (coldest seawater temperatures, highlighted with numbers). The data were smoothed using 5-point Savitsky-Golay filter. (b) The shell drill-sampled for the data in (a); visible drill tracks are highlighted with red marks; black arrow denotes where sampling at the apex ceased. This nonsampled area corresponds to the hatched area in (a). The shell tip of this specimen was lost due to damage. (c) Photomicrograph of the matching statolith from the individual in (a) and (b), showing the nucleus (N), hatching ring (HR) and annual bands (numbers). $(d-f)$ shows the same as $(a-c)$ respectively for an older male specimen exists between statolith diameter and shell length; however, the wide variation in statolith diameters that exists in large $(>60 \mathrm{~mm})$ and older whelks means that it is not possible to estimate an older whelk's age solely from statolith size. The age of each whelk must be determined by counting the number of annually resolved statolith rings. The annual periodicity of the growth rings was further validated with the reconstruction of $\delta^{18} \mathrm{O}$ profiles from shells (Fig. 7). This is the same method used by Santarelli \& Gros (1985) to validate the observable growth rings in the opercula. However, in this study a higher sampling resolution was used, producing more clearly defined $\delta^{18} \mathrm{O}$ cycles that are directly overlaid on the visible growth rings of the statolith. Santarelli \& Gros (1985) did not demonstrate the ages of the animals from the opercula.

\section{Statolith composition}

The statoliths of $B$. undatum are composed of aragonite, as shown by Raman spectra indicating no visible trace of calcite. There was close agreement between the aragonite standard and the sample spots taken from the statolith, although several of the reported Raman spectra peaks differed by 1 to $3 \mathrm{~cm}^{-1}$ compared with those reported in the literature (see Parker et al. 2010). It is probable that this difference between the observed statolith spectra peaks and the published spectra was caused by the presence of trace elements such as $\mathrm{Mg}^{2+}$ substituting for $\mathrm{Ca}^{2+}$ within the lattice and distorting it (Parker et al. 2010). This would explain why the synthetic calcite standard exhibited all of the expected peaks whereas the sample spots and the speleothem aragonite standard (which can contain trace elements; Finch et al. 2001) did not. The Raman spectra of the sample spots also exhibited a diffuse band between 2850 and $3000 \mathrm{~cm}^{-1}$, which likely indi- 
cates the presence of structural organic matter within the $\mathrm{CaCO}_{3}$ matrix. All 3 of the spot samples showed a peak in the spectra, likely indicating the presence of organic matter throughout the statolith matrix, although the most intense peak was observed when the structure of a growth ring was coincidentally analysed (spot 3 on the statolith). A similar conclusion was reached by Galante-Oliveira et al. (2014) who observed similar spectra in the statoliths of Nassarius reticulatus. If the Raman peaks represent differences in the concentration of organic matter present in different parts of the statolith, then this will aid in interpreting the distribution of elements such as Sr and $\mathrm{Mg}$ in the statolith. In N. reticulatus, annual cycles of $\mathrm{Sr}$ :Ca ratios were found to correspond with the visible growth rings (Galante-Oliveira et al. 2015) with minimum ratios associated with the rings and maximum concentrations present in the increments between adjacent rings. Schöne et al. (2010) demonstrated the role of organic material in bivalve shells in regulating the control of biogenic element incorporation into the shell structure, highlighting that insoluble organic matter present in the aragonitic shell of Arctica islandica is significantly enriched in $\mathrm{Mg}$ and depleted in Sr.

\section{Implications for fisheries}

With the development of this ageing technique for such a commercially important species, the construction and comparison of population growth curves can be easily implemented on a potentially large scale. Vast improvements over the operculum age determination method have been shown, with a decrease in discarded samples from 48 to $8.4 \%$ and an increase in useable samples from 52 to $91.6 \%$. Whilst the methodology for statolith extraction and analysis is potentially more time consuming than the use of opercula, the huge increase in reliability and decrease in potential sample bias (from large discards) is clear.

\section{CONCLUSIONS}

Here, an annually resolved periodicity of growth ring formation in whole resin-mounted statoliths from Buccinum undatum was validated by comparison with seasonally collected and laboratory-reared juvenile whelks of known age, and from similarities between growth rings and the $\delta^{18} \mathrm{O}$ cycles in their shells. This validated, novel age determination tool (using statoliths) can be used to accurately reconstruct the population structure and population growth rates of $B$. undatum, and the technique will now be available for fisheries scientists to undertake stock assessments of whelk populations Europeanwide to determine both size-at-age and age at reproduction. These are both metrics that will aid in future management decisions. The statoliths present a viable alternative to the 'difficult to use' opercula. $B$. undatum statoliths are composed of aragonitic calcium carbonate and their structure, determined by Raman-Microscopy, has revealed variations in organic matter throughout the statolith that might have implications for the way in which biogenic elements are incorporated into the organic lattice of the statolith. Overall, we conclude that understanding differences in the age, growth rate and distributions of whelks in coastal waters will add immeasurably to our understanding of how to manage and conserve these important scavengers in coastal zones.

Acknowledgements. This work was supported through a Bangor University/CEFAS partnership PhD scholarship to P.R.H. We are grateful to Gwynne Parry-Jones for collecting Buccinum undatum from the Menai Strait. The IRMS analyses were supported by a NERC Isotope Geosciences Facilities Steering Committee (IP-1527-0515) award, and thanks to Hilary Sloane for technical support. Access to the Reinshaw Raman-Microscope was made possible through a rapid access request to the Diamond Light Source (SP13616-1). Production of the SEM micrographs would not have been possible without the help of Dr. Lorraine Field (BGS) and Dr. Andy Marriott (BGS). A number of colleagues and students, Richard Patton, Charlotte Colvin, Helèna Bonici, Anton Antonov and Devaney Werrin are acknowledged for their invaluable help with animal husbandry. We also thank Dr. Ewan Hunter and Dr. Andy Marriott, and 3 anonymous reviewers whose comments greatly improved the manuscript. M.J.L. and S.R.N.C. publish with the permission of the Director British Geological Survey (BGS); P.R.H. is registered as a BUFI student within BGS.

\section{LITERATURE CITED}

Arkhipkin AI (2005) Statoliths as 'black boxes' (life recorders) in squid. Mar Freshw Res 56:573-583

Barroso CM, Nunes M, Richardson CA, Moreira MH (2005) The gastropod statolith: a tool for determining the age of Nassarius reticulatus. Mar Biol 146:1139-1144

Beesley PL, Ross GJB, Glasby CJ (eds) (2000) Polychaetes and allies: the southern synthesis. Fauna of Australia, Vol 4A: Polychaeta, Myzostomida, Pognophora, Echiura, Sipuncula. CSIRO publishing, Melbourne

* Brinza L, Schofield PF, Mosselmans JFW, Donner E, Lombi E, Paterson D, Hodson ME (2014) Can earthwormsecreted calcium carbonate immobilise Zn in contaminated soils? Soil Biol Biochem 74:1-10

Chase R (2002) Behaviour and its neural control in gastropod molluscs. Oxford University Press, New York, NY 
Chatzinikolaou E, Richardson CA (2007) Evaluating the growth and age of the netted whelk Nassarius reticulatus (Gastropoda: Nassaridae) from statolith growth rings. Mar Ecol Prog Ser 342:163-176

Craig H (1957) Isotopic standards for carbon and oxygen and correction factors for mass spectrometric analysis. Geochim Cosmochim Acta 12:133-149

* Devon \& Severn IFCA (Inshore Fisheries and Conservation Authority) (2016) www.devonandsevernifca.gov.uk/devonsevern-ifca-whelk-research-2016 (accessed 1 Jul 2016)

Eastern IFCA (2016) www.eastern-ifca.gov.uk/emergencywhelk-byelaw/ (accessed 1 Jul 2016)

Ehlers U (1997) Ultrastructure of the statocysts in the apodous sea cucumber Leptosynapta inhaerens (Holothuroidea, Echinodermata). Acta Zool 78:61-68

Epstein S, Buchsbaum JR, Lowenstam HA, Ukey HC (1953) Revised carbonate-water isotopic temperature scale. Geol Soc Am Bull 64:1315-1326

Espeel M (1985) Fine structure of the statocyst sensilla of the mysid shrimp Neomysis integer (Leach, 1814) (Crustacea, Mysidacea). J Morphol 186:149-165

Fahy E, Masterson E, Swords D, Forrest N (2000) A second assessment of the whelk fishery Buccinum undatum in the southwest Irish Sea with particular reference to its history of management by size limit. Irish Fisheries Investigations 6, Marine Institute, Dublin

Fahy E, Carroll J, O'Toole M, Barry C, Hother-Parkes L (2005) Fishery associated changes in the whelk Buccinum undatum stock in the southwest Irish Sea, 19952003. Irish Fisheries Investigations 15, Marine Institute, Dublin

Ferreira T, Rasband W (2012) ImageJ user guide-IJ 146r. National Institutes of Health, Bethesda, MD. https:// imagej.nih.gov/ij/docs/guide/

Finch AA, Shaw PA, Weedon GP, Holmgren K (2001) Trace element variation in speleothem aragonite: potential for palaeoenvironmental reconstruction. Earth Planet Sci Lett 186:255-267

Galante-Oliveira S, Marçal R, Ribas F, Machado J, Barroso C (2013) Studies on the morphology and growth of statoliths in Caenogastropoda. J Molluscan Stud 79:340-345

Galante-Oliveira S, Marçal R, Guimarães F, Soares J, Lopes JC, Machado J, Barroso C (2014) Crystallinity and microchemistry of Nassarius reticulatus (Caenogastropoda) statoliths: towards their structure stability and homogeneity. J Struct Biol 186:292-301

Galante-Oliveira S, Marçal R, Espadilha F, Sá M, Abell R, Machado J, Barroso C (2015) Detection of periodic Sr $\mathrm{Ca}^{-1}$ cycles along gastropod statoliths allows the accurate estimation of age. Mar Biol 162:1473-1483

* Gentry DK, Sosdian S, Grossman EL, Rrosenthal Y, Hicks D, Lear CH (2008) Stable isotope and $\mathrm{Sr} / \mathrm{Ca}$ profiles from the marine gastropod Conus ermineus: testing a multiproxy approach for inferring paleotemperature and paleosalinity. Palaios 23:195-209

Grossman EL, Ku T (1986) Oxygen and carbon isotope fractionation in biogenic aragonite: temperature effects. Chem Geol 59:59-74

Haig JA, Pantin JR, Murray LG, Kaiser MJ (2015) Temporal and spatial variation in size at maturity of the common whelk (Buccinum undatum). ICES J Mar Sci 72:2707-2719

Higson SPJ (2006) Analytical chemistry. Oxford University Press, New York, NY

Kent \& Essex IFCA (2016) www.kentandessex-ifca.gov.uk/ i-want-to-find-out-about/regulations/keifca-byelaws/ keifca-district-byelaws/ (accessed 1 Jul 2016)

Kideys AE (1996) Determination of age and growth of Buc- cinum undatum L. (Gastropoda) off Douglas, Isle of Man. Helgol Meeresunters 50:353-368

Kosyan AR, Antipushina ZA (2011) Determination of Rapana venosa individuals' ages based on the $\delta^{18} \mathrm{O}$ dynamics of the shell carbonates. Oceanology (Mosc) 51:1021-1028

Lawler A (2013) Determination of the size of maturity of the whelk Buccinum undatum in English waters - DEFRA Project MF0231. http://randd.defra.gov.uk/Default.aspx? Module $=$ More $\&$ Location $=$ None $\&$ ProjectID $=17916$

* Leng MJ, Lewis JP (2016) Oxygen isotopes in molluscan shell: applications in environmental archaeology. Environ Archaeol 21:295-306

Magnúsdóttir H (2010) The common whelk (Buccinum undatum L.): life history traits and population structure. MSc thesis, University of Iceland, Reykjavik

MMO (Marine Management Organisation) (2016) UK sea fisheries statistics 2015. Office for National Statistics, London

McIntyre R, Lawler A, Masefield R (2015) Size of maturity of the common whelk, Buccinum undatum: Is the minimum landing size in England too low? Fish Res 162:53-57

Morton B (1985) Statocyst structure in the Anomalodesmata (Bivalvia). J Zool 206:23-34

Nasution S (2003) Intra-capsular development in marine gastropod Buccinum undatum (Linnaeous 1758). J Natur Indones 5:124-128

Nasution S, Roberts D, Farnsworth K, Parker GA, Elwood RW (2010) Maternal effects on offspring size and packaging constraints in the whelk. J Zool (Lond) 281:112-117

Pálsson $\mathrm{S}$, Magnúsdóttir $\mathrm{H}$, Reynisdóttir $\mathrm{S}$, Jónsson ZO, Örnólfsdóttir EB (2014) Divergence and molecular variation in common whelk Buccinum undatum (Gastropoda: Buccinidae) in Iceland: a trans-Atlantic comparison. Biol J Linn Soc 111:145-159

Parker JE, Thompson SP, Lennie AR, Potter J, Tang CC (2010) A study of the aragonite-calcite transformation using Raman spectroscopy, synchrotron powder diffraction and scanning electron microscopy. CrystEngComm 12:1590-1599

Richardson CA (2001) Molluscs as archives of environmental change. Oceanogr Mar Biol Annu Rev 39:103-164

* Richardson CA, Saurel C, Barroso CM, Thain J (2005a) Evaluation of the age of the red whelk Neptunea antiqua using statoliths, opercula and element ratios in the shell. J Exp Mar Biol Ecol 325:55-64

Richardson CA, Kingsley-Smith PR, Seed R, Chatzinikolaou E (2005b) Age and growth of the naticid gastropod Polinices pulchellus (Gastropoda: Naticidae) based on length frequency analysis and statolith growth rings. Mar Biol 148:319-326

Santarelli L, Gros P (1985) Age and growth of the whelk Buccinum undatum L. (Gastropoda: Prosobranchia) using stable isotopes of the shell and operculum striae. Oceanol Acta 8:221-229

Schöne BR, Zhang Z, Jacob D, Gillikin DP and others (2010) Effect of organic matrices on the determination of the trace element chemistry $(\mathrm{Mg}, \mathrm{Sr}, \mathrm{Mg} / \mathrm{Ca}, \mathrm{Sr} / \mathrm{Ca})$ of aragonitic bivalve shells (Arctica islandica) - comparison of ICP-OES and LA-ICP-MS data. Geochem J 44:23-37

Sharma T, Clayton RN (1965) Measurement of ${ }^{18} \mathrm{O} /{ }^{16} \mathrm{O}$ ratios of total oxygen of carbonates. Geochim Cosmochim Acta 56:419-430

* Shelmerdine RL, Adamson J, Laurenson CH, Leslie B (2007) Size variation of the common whelk, Buccinum undatum, over large and small spatial scales: potential implications for micro-management within the fishery. Fish Res 86: 201-206 
Shrives JP, Pickup SE, Morel GM (2015) Whelk (Buccinum undatum L.) stocks around the Island of Jersey, Channel Islands: reassessment and implications for sustainable management. Fish Res 167:236-242

Smith E, Dent G (2005) Modern Raman spectroscopy: a practical approach. John Wiley \& Sons, Chichester

Smith KE, Thatje S (2013) Nurse egg consumption and intracapsular development in the common whelk Buccinum undatum (Linnaeus, 1758). Helgol Mar Res 67: 109-120

Steinier J, Termonia Y, Deltour J (1972) Comments on smoothing and differentiation of data by simplified least square procedure. Anal Chem 44:1906-1909

Ten Hallers-Tjabbes CC, Evaraarts JM, Mensink BP, Boon JP (1996) The decline of the North Sea whelk (Buccinum undatum L.) between1970-1990: A natural or a human-

Editorial responsibility: Yves Cherel, Villiers-en-Bois, France induced event? Mar Ecol 17:333-343

*Warton DI, Duursma RA, Falster DS, Taskinen S (2015) R package 'smatr': (standardised) major axis estimation and testing routines. https://cran.r-project.org/web/packages/ smatr/index.html

* Weetman D, Hauser L, Bayes MK, Ellis JR, Shaw PW (2006) Genetic population structure across a range of geographic scales in the commercially exploited marine gastropod Buccinum undatum. Mar Ecol Prog Ser 317: 157-169

Wheeler AP (1992) Mechanisms of molluscan shell formation. In: Bonucci E (ed) Calcification in biological systems. CRC Press, Boca Raton, FL, p 179-216

Wilbur KM, Saleuddin AS (1983) Shell formation. In: Wilbur KM (ed) The Mollusca, Vol 4: physiology. Academic Press, New York, NY, p 235-237

Submitted: February 1, 2017; Accepted: March 13, 2017

Proofs received from author(s): April 10, 2017 